Revista de la Escuela de Ciencias de la Educación, año 13, nRo. 12, vol. 1, enero a Junio de 2017. PÁginas 9-22. ISSN 1851-6297. ISSN 2362-3349 (EN LINEA). UMA PROPOSTA METODOLÓGICA: A CIRANDA CARTOGRÁFICA DE SABERES E CONHECIMIENTOS. AlCIDES Leão SANTOS JúNIOR

\title{
UMA PROPOSTA METODOLÓGICA: A CIRANDA CARTOGRÁFICA DE SABERES E CONHECIMENTOS
}

\author{
Por Alcides Leão Santos Júnior* \\ Universidade do Estado do Rio Grande do Norte, Brasil. \\ santosjunioralcides@gmail.com
}

Recibido: 22/07/2016 Aceptado: 05/09/2016

\section{Resumo}

Descreve-se a Ciranda Cartográfica de Saberes e Conhecimentos como um dispositivo de pesquisa. Faz-se uso da Cartografia como um instrumento de preservação da representação do espaço não explorado, percorrido, visitado e experienciado pelos sujeitos. A proposta tem embasamento no pensamento do sociólogo Boaventura de Sousa Santos e procura evidenciar saberes e conhecimentos com o uso da representação como uma possibilidade de comunicação para traduzir graficamente saberes e conhecimentos e desnudar as falas dos sujeitos, de uma pesquisa de natureza qualitativa, articulando-as aos objetivos da mesma a fim de contribuir para uma leitura sem o direcionamento ou tratamento. Aponta-se que o dispositivo ao ser utilizado em uma pesquisa permite ao pesquisador uma maior aproximação com os sujeitos da sua pesquisa, bem como possibilita aos leitores (re)leituras do que foi pesquisado.

Pedagogo; Doutor em Educação (UFBA); professor do Departamento de Educação, do Campus Assú, da Universidade do Estado do Rio Grande do Norte e do Programa de Pós-Graduação em Planejamento e Dinâmicas Territoriais do Semiarido (PLANDITES/ UERN). 
Revista de la Escuela de Ciencias de la Educación, año 13, nRo. 12, vol. 1, enero a junio de 2017. Páginas 9-22. ISSN 1851-6297. ISSN 2362-3349 (EN LINEA). UMA PROPOSTA METODOLÓGICA: A CIRANDA CARTOGRÁFICA DE SABERES E CONHECImientos. Alcides Leão Santos Júnior

Palavras Chave: Cartografia - Epistemologia - Metodologia das ciências.

\section{Abstract}

Describes the Ring of knowledge and Knowledge Cartography as a research device. Make use of cartography as a tool of preservation of untapped space representation, traveled, visited and experienced by the subject. The proposal has support at the thought of the sociologist Boaventura de Sousa Santos and seeks to demonstrate knowledge and expertise with the use of representation as a possibility of communication to translate knowledge and knowledge and graphically strip lines of the subject, a research of qualitative nature, articulating them to the same objectives in order to contribute to a reading without targeting or treatment. Points to the device to be used in a survey allows the researcher a closer relationship with the subjects of his research, as well as enable new readers (re) readings of what was searched.

Keywords: Cartography - Epistemology - Methodology of science

\section{Introdução}

Em uma sociedade que prima pela produção do conhecimento, percebese que ao longo dos tempos os humanos têm procurado utilizar os mais variados dispositivos (1) para conservar e socializar suas experiências. Dessa forma, encontramos nas pesquisas acadêmicas um meio para que outros sujeitos possam conhecê-las ou até mesmo para produzir e colaborar com a construção da História da Humanidade.Diante desse repertório, indagamos: é possível através de uma metodologia de pesquisa evidenciar saberes e conhecimentos do vivido tornando os autores protagonistas da sua experiência?

Através dessa indagação, procuramos compor um trilhar metodológico para a escrita de uma tese no Programa de Pós-Graduação em Educação, da Universidade Federal da Bahia (UFBA), defendida em 28/02/13, intitulada A extensão universitária e os entre-laços de saberes. A orientação teóricometodológica está ancorada no pensamento de Boaventura de Sousa Santos (2005, 2004, 2000) quando o mesmo trata da Sociologia das Ausências e Emergências e, sobretudo, sobre a Cartografia Simbólica. O nosso trilhar recebeu a denominação de Ciranda Cartográfica de Sabres e Conhecimentos. Dessa forma, pretendemos aqui descrever os artifícios e ritmos utilizados para a composição do caminhar.

Inicialmente é preciso postular que evidenciar as maneiras pelas quais imaginamos os discursos do "outro" nos permite mapear as experiências vivenciadas pelos sujeitos de forma que as representações possam ganhar (ou não) notoriedade. Assim, como dispositivo de pesquisa, indicamos a Ciranda Cartográfica de Saberes e Conhecimentos como um meio para evidenciar 
Revista de la Escuela de Ciencias de la Educación, año 13, nRo. 12, vol. 1, enero a junio de 2017. Páginas 9-22. ISSN 1851-6297. ISSN 2362-3349 (EN LINEA). UMA PROPOSTA METODOLÓGICA: A CIRANDA CARTOGRÁFICA DE SABERES E CONHECIMIENTOS. Alcides Leão SANTOS JúNIOR

memórias e experiências do vivido.

Ao apontarmos a Ciranda Cartográfica de Saberes e Conhecimentos como um dispositivo de pesquisa,a nossa apreensão inicial parte da compreensão que a Cartografia é um instrumento ou dispositivo de conservação e preservação da representação do espaço não explorado, percorrido, visitado e experienciado pelos sujeitos. Sendo assim, ao descrevermos como a Ciranda Cartográfica de Saberes e Conhecimentos surge como um dispositivo de pesquisa, lembramos que Joly (1990, p. 31) nos diz que, ao longo do tempo, os homens: "aprenderam a gravar os seus detalhes em placas de argilas, madeira ou metal, ou desenhá-los nos tecidos, nos papiros e nos pergaminhos. Assim, aprenderam no Egito, na Assíria, na Fenícia e na China os primeiros esboços cartográficos".

A utilização da cartografia é muito difundida na história da humanidade e serviu tanto para os comerciantes quanto para os militares defenderem os limites de seus Estados. Os primeiros mapas foram traçados a partir de relatos orais de viajantes; hoje, já vimos que os satélites espalhados pelo cosmos mostram como a realidade e os espaços são mutáveis. Isso também favoreceu o uso de cartografia para registros de saberes e bens imateriais em determinados espaços sociais e culturais como forma de preservação do lugar no cotidiano como diria Milton Santos (2000).

Não queremos fazer ou traçar, aqui, um histórico da cartografia, mesmo porque este não é nosso objeto de estudo e, também, porque existe uma gama de referências que dão conta dessa questão. O próprio Boaventura de Sousa Santos oferece-nos uma consistente articulação entre referências teóricas da geografia com a teoria social das representações quando nos propõe a tal Cartografia das Representações Sociais do Direito (Santos, 2000). Nossa proposta centra-se apenas em evidenciar saberes e conhecimentos com o uso desta forma de representação como uma possibilidade de comunicação para traduzir graficamente saberes e conhecimentos.

A proposta que ora se delineia para o aporte metodológico ganha força no dizer de Cunha (2006) quando advoga que:

Apesar de muitas vezes se recuperarem vozes silenciadas, as formas de pensar e processar estas fontes de conhecimentos não romperam, na maior parte dos casos e no fundamental, com os paradigmas dominantes que são perspectivas constitutivas do conhecimento dominante. Nesta medida, a geopolítica do conhecimento não é mais uma abordagem epistemológica, mas é o lugar político da ciência. O postulado da diferença, da heterogeneidade, da mestiçagem, da hibridização, da contingência, é profundamente político e tem que ser levado a sério, sob pena de se estabelecerem apenas trocas desiguais (Cunha, 2006, p.11).

Tentando não estabelecer trocas desiguais entre os sujeitos da pesquisa 
Revista de la Escuela de Ciencias de la Educación, año 13, nRo. 12, vol. 1, enero a junio de 2017. Páginas 9-22. ISSN 1851-6297. ISSN 2362-3349 (EN LINEA). UMA PROPOSTA METODOLÓGICA: A CIRANDA CARTOGRÁFICA DE SABERES E CONHECImientos. Alcides Leão Santos Júnior

e o pesquisador, enfatizamos que a opção em trabalhar com a Cartografia Simbólica ou com a Sociologia Cartográfica proposta por Santos (2005, 2004, 2000) remonta à questão de que tal dispositivo ou procedimento de sistematização de informações nos conduz à compreensão de que a ciência é complexa e combina características tanto das Ciências Naturais quanto das Ciências Sociais (Santos, 2005, p. 197). Assim, uma Cartografia pode satisfazer a intenção de evidenciar conhecimentos antagônicos em modos comunicativos acessíveis favorecendo o processo de construção de conhecimento nas diversas áreas do conhecimento.

Esclarecemos que a Associação Cartográfica Internacional, conforme Joly, em reunião na UNESCO, em abril de 1966, em Paris, definiu a cartografia como

(...) o conjunto dos estudos e das operações científicas, artísticas e técnicas que intervém a partir dos resultados de observações diretas ou da exploração de uma documentação, em vista da elaboração e do estabelecimento de mapas, planos e outros modos de expressão, assim como de sua utilização (Joly, 1990, pp. 8 - 9).

A partir de um estudo sobre a utilização da Cartografia, Brito e Hetkowski (2009) informa que este conceito considera:

(...) que os usuários dos produtos cartográficos também estão produzindo cartografia, pois existe uma clara interação entre os mapas e seus usuários. Interação esta relacionada com a representação dos elementos ou fenômenos, bem como com a sua interpretação. Assim, podemos tomar a Cartografia como linguagem, uma forma de apresentar e representar a superfície terrestre e seus elementos através de um alfabeto próprio, o qual se utiliza signos (símbolos), bem como de figuras geométricas (pontos, linhas e polígonos) na composição de suas mensagens (Brito e Hetkowski, 2009, s.p.).

Diante dessa observação, podemos inferir que a Cartografia é uma estratégia de suspensão do tempo, que cria ambiente para o espaço que engloba, segundo Joly (1990, p. 9), parte de "(...) todas as atividades que vão do levantamento do campo ou da pesquisa bibliográfica até a impressão definitiva e a publicação do mapa elaborado". Dessa forma, esta suspensão se dá porque os acontecimentos históricos fazem parte da ontologia do ser e podem ser combinados entre o ontem, o hoje e o amanhã em um movimento que direciona a essência do humano que vive, constrói e imagina sua realidade, buscando concretizar seus ideais.

Merece destaque aqui o uso que o leitor faz dos mapas, pois, conforme Brito e Hetkowshi (2009), a junção entre os conhecimentos do:

(...) emissor e do receptor propicia o crescimento científico, em que saber 
Revista de la Escuela de Ciencias de la Educación, año 13, nRo. 12, vol. 1, enero a Junio de 2017. PÁginas 9-22. ISSN 1851-6297. ISSN 2362-3349 (EN LINEA). UMA PROPOSTA METODOLÓGICA: A CIRANDA CARTOGRÁFICA DE SABERES E CONHECImientos. Alcides Leão SANTOS JúNIOR

individual é transposto. Desta forma, a informação que sai é maior do que a que entra: a informação é objetiva, pois foi produzida sistematicamente através de um método científico, mas a interpretação pode sofrer influências por parte de cada especificidade dos leitores (Brito e Hetkowski, 2009, s.p.).

É com esse dimensionamento que projetamos a Cartografia enquanto dispositivo de pesquisa que procura sistematizar seus dados em um mapa elaborado cujo conteúdo informe a dinâmica do espaço/tempo experienciado pelos sujeitos da pesquisa. Assim, se a Cartografia relaciona o tempo geográfico ao histórico, podemos entender que este dispositivo possa ser "[...] antes de tudo uma mensagem de localização e de avaliação de distancias e de orientações" (Joly, 2004, p. 9); no caso em pauta, de orientação para a prática universitária.

Como temos enquanto aporte teórico embasamento no Pensamento Complexo, não é demais lembrar que Morin (2007, p. 192) nos diz que a complexidade não possui uma metodologia, mas esta pode terum método e como nossa tese é de que na extensão universitária de cunho acadêmico as fronteiras disciplinares dissipam-se, a nossa ideia é fazer com que estes saberes e conhecimentos possam dialogar. Assim, esta proposta metodológica foi construída quando escrevemos nossa tese de doutoramento em educação, na Universidade Federal do Estado da Bahia (UFBA), que versava sobre a produção de conhecimentos dos estudantes egressos dos cursos de graduação da UFBA que participaram de uma ação extensionista denominada Atividade Curricular em Comunidade (ACC).

A ACC é uma ação de extensão universitária que não subestima os saberes e conhecimentos produzidos no/pelo senso comum, pois o que se aprende na academia não pode, nem deve, ser entendido como superior a ponto de sobrepor as informações que se tem nas comunidades. Esta atitude, no nosso entendimento, faz as diversas experiências vivenciadas pelos sujeitos sociais produzirem saberes e mostrarem que o conhecimento científico somente tem sentido quando articulado com outros saberes/conhecimentos. Para a escrita da tese que visava difundir a produção de conhecimento pela via do entrelaçamento Universidade e Sociedade,propomos a Ciranda Cartográfica de Saberes e Conhecimentos como percurso metodológicos que surgiu como um dispositivo de pesquisa que procura desnudar as falas dos sujeitos, de uma pesquisa de natureza qualitativa, articulando-as aos objetivos da mesma a fim de contribuir para uma leitura sem o direcionamento ou tratamento às falas, às narrativas, às histórias de vida e às memórias dos sujeitos da pesquisa. Ela é uma forma de diálogo entre o pesquisador com os sujeitos da pesquisa e que pode ser (re)lida com outros olhos pelos leitores.

O conhecimento incorporado para projetar a Ciranda Cartográfica de Saberes e Conhecimentos origina-se, também, em uma tentativa de exercício e procura por uma justiça cognitiva que muitas vezes não é dada quando faze- 
Revista de la Escuela de Ciencias de la Educación, año 13, nRo. 12, vol. 1, enero a junio de 2017. Páginas 9-22. ISSN 1851-6297. ISSN 2362-3349 (EN LINEA). UMA PROPOSTA METODOLÓGICA: A CIRANDA CARTOGRÁFICA DE SABERES E CONHECImientos. Alcides Leão Santos Júnior

mos tratamentos das falas dos sujeitos na pesquisa acadêmica.

Assim, o primeiro contato e interesse pela metodologia tem sua gênese quando participávamos do Grupo de Estudos Boaventura, um grupo da linha de pesquisa em Educação, Estado e Sociedade, do Programa de Pós-Graduação em Ciências Sociais (PPGCS) da Universidade Federal do Rio Grande do Norte (UFRN), grupo que frequentávamos no momento quando estávamos matriculados como estudante no referido PPGCS-UFRN e, neste, alguns pesquisadores estavam desenvolvendo seus trabalhos fazendo uso da Cartografia Simbólica com base no pensamento de Boaventura de Sousa Santos. Assim, podemos apontar a pesquisa de Silva (2006) intitulada "Memória da Formação médica da Universidade Federal do Rio Grande do Norte/Brasil' que objetivou constituir ahistória do curso médico da UFRN em seus momentos iniciais (1955-1963) fazendo uso da memória de estudantes egressos das primeiras turmas do curso de medicina da UFRN. Através delembranças, dos estudantes egressos das primeiras turmas do curso de medicina da UFRN, apontou-se a Cartografia como um procedimento metodológico sedimentado em "uma abordagemnão paramétrica com enfoque qualitativo" outra pesquisa que utilizou a metodologia da Cartografia foi a Nobre (2003) que apresenta as potencialidades da fotografia como narrativa visual a partir de umavisão dialógica da pesquisa realizada nas comunidades de Venha Ver e Diogo Lopes (Macau/RN/BR), tendo como técnicas de coleta de dados a observação, a entrevista, oregistro fotográfico, a pesquisa documental e a análise qualitativa, compondo umacartografia simbólica. Na proposta de Nobre (2003) denominada "Foto-Cartografia" ao examinar uma mensagem fotográfica o interpretante constrói um entendimento a respeito de si e do outro, de suas formas de agir, viver ese relacionar com suas práticas, penetrando um cotidiano social que não é o seu,podendo, assim, constituir-se em um caminho pelo qual o sujeito pode adentrar, voltar, refazer ereconhecer o seu próprio percurso social, religando-se ao seu plano histórico-cultural.

Na nossa proposta, em termos de conteúdo, a Ciranda Cartográfica de Saberes e Conhecimentos apresenta uma composição simbólica que procura trazer informações ao leitor sobre o vivido/vivenciado. O mapa que procuramos esboçar constitui-se em um conjunto de símbolos, de letras e de cores, de modo que sua mensagem possa ser entendida com facilidade (Duarte, 1991).

Em relação ao conteúdo informacional de um mapa, podemos ainda destacar que ele pode ser utilizado como possibilitador de leitura e de representação. Desse modo, mesmo com o advento do avanço das tecnologias, Rodrigues e Souza (2008) nos diz que a informação é um:

(...) documento cartográfico tem escala e uma organização espacial baseada numa projeção ortogonal da superfície terrestre sobre o plano. A representação da mensagem por meio de signos encontra-se diretamente 
Revista de la Escuela de Ciencias de la Educación, año 13, nRo. 12, vol. 1, enero a Junio de 2017. PÁginas 9-22. ISSN 1851-6297. ISSN 2362-3349 (EN LINEA). UMA PROPOSTA METODOLÓGICA: A CIRANDA CARTOGRÁFICA DE SABERES E CONHECIMIENTOS. Alcides Leão SANTOS JúNIOR

condicionada à característica do fenômeno e aos dados disponíveis. Neste caso, são os signos projetados, modificados e agrupados individualmente, que refletem o propósito de um determinado mapa, por meio de uma dada composição simbólica (Rodrigues e Souza, 2008, p. 66).

A proposta que se delineia de apresentarmos uma Ciranda Cartográfica de Saberes e Conhecimentos ganha força a partir do pensamento de Borba (1998, p. 17) quando diz que precisamos sair do conformismo das metodologias prontas. Pois, no "[...] fazer ciência, o criar, o construir ciência que definirá a "composição" (a bricolagem) metodológica. É na construção do campo de pesquisa que se define a elaboração (in loco) das metodologias (a composição inteligente das mesmas), e não o inverso".

A nossa tentativa de transgressão configura-se em (re)criar e mapear os diálogos entre sujeitos da nossa pesquisa. Isso porque "[...] o conhecimento oriundo da análise multirreferencial é "tecido" (bricolado): ele se estabelece a partir da convergência, ou melhor, da convivência, do diálogo trans, pluri, interdisciplinarmente" (Martins, 1998, p. 23). Assim, nosso mapa de entrelaçamentos de saberes e conhecimentos parte das vivências e possui a seguinte configuração:

FIGURA Nº1 - CIRANDA CARTOGRÁFICA DE SABERES E CONHECIMENTOS

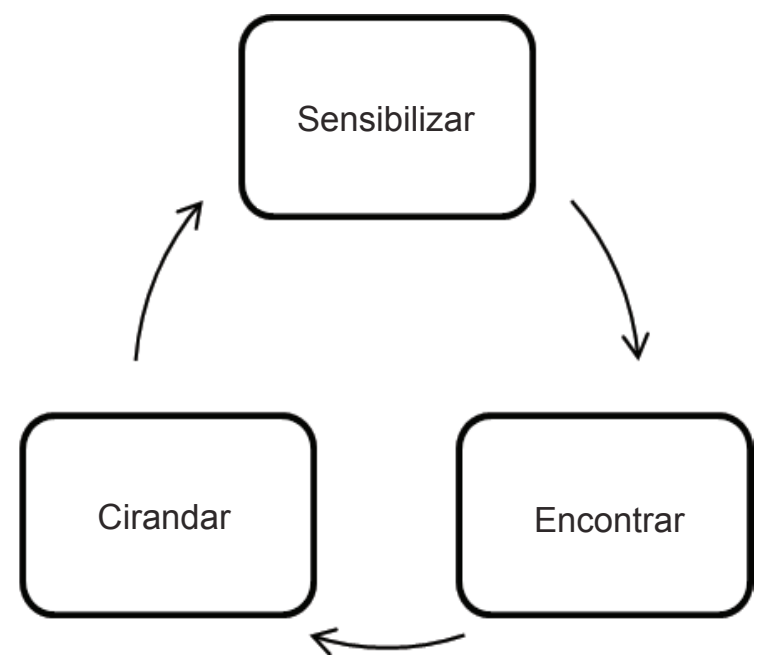

Fonte: Santos Júnior (2013, p. 154) 
Revista de la Escuela de Ciencias de la Educación, año 13, nRo. 12, vol. 1, enero a junio de 2017. Páginas 9-22. ISSN 1851-6297. ISSN 2362-3349 (EN LINEA). UMA PROPOSTA METODOLÓGICA: A CIRANDA CARTOGRÁFICA DE SABERES E CONHECImientos. Alcides Leão Santos Júnior

As expressões que aparecem na Figura $N^{\circ}$ 01(sensibilizar, encontrar e cirandar) dizem respeito aos momentos de desenvolvimento da pesquisa a partir da forma com a qual estabelecemos os encontros com os sujeitos da pesquisa. Dessa forma, o cirandar corresponde a uma brincadeira de crianças bastante comum no Nordeste do Brasil que evidencia a não hierarquização de saberes. Essas brincadeiras mostram que não há um saber hierárquico, tampouco uma centralidade, pois em uma ciranda todos estão no mesmo patamar; todos se olham, se veem, se enxergam e se sentem, se ouvem e se movimentam em um mesmo ritmo acompanhando as canções da ciranda. No interior da ciranda, saberes e fazeres circulam, alteram-se e transformam-se conforme as posições e os diferentes ritmos de participação daqueles que congregam a experiência vivida na produção do conhecimento.

O sensibilizar assenta na conversação e na forma como o pesquisador vai ao encontro do sujeito da pesquisa procurando sempre evidenciar uma convivência democrática entre diferentes saberes e conhecimentos baseada no respeito à diferença, que se caracteriza no reconhecimento do "outro". Dessa forma, lembramo-nos das palavras de Ardoino (apud Borba, 2012, p. 82) quando nos diz que "o conhecimento científico, ao invés de ser uma Torre de Babel, deve ser poliglota".

Como se trata de uma proposta metodológica que visa aproximar diferenças étnico-culturais e sociais promovendo um entrelaçamento de saberes, fazendo uso do encontro e produzindo traduções interculturais dos saberes produzidos, vislumbramos este momento como sendo um deslocamento intercultural para mapear as falas dos sujeitos de uma pesquisa.

Fleury (2003, p. 17) comenta que o adjetivo intercultural "[...] tem sido utilizado para indicar realidades e perspectivas incongruentes entre si: há quem o reduz ao significado de relação entre grupos "folclóricos"; há quem amplia o conceito de interculturalidade de modo a compreender o "diferente" que caracteriza a singularidade e a irrepetibilidade de cada sujeito humano; há ainda quem considera interculturalidade como sinônimo de "mestiçagem". Ainda sobre a interculturalidade, Pimentel (2012) completa afirmando que:

(...) como dinâmica do encontro e da complementariedade na diversidade, é uma das interpretações apreensíveis das contribuições de Boaventura de Sousa Santos para a compreensão da escola e dos espaços não escolares de produção de conhecimento como paradigmas de organizações sociais planetárias na contemporaneidade, também produtores de ecologias de saberes que exigem novas traduções interculturais (Pimentel, 2012, p. 24).

A interculturalidade, assim, pode ser entendida como um momento de conversação que coloca ênfase no respeito, no direito a ser diferente e na denún- 
Revista de la Escuela de Ciencias de la Educación, año 13, nRo. 12, vol. 1, enero a Junio de 2017. PÁginas 9-22. ISSN 1851-6297. ISSN 2362-3349 (EN LíNEA). UMA PROPOSTA METODOLÓGICA: A CIRANDA CARTOGRÁFICA DE SABERES E CONHECImientos. Alcides Leão SANTOS JúNIOR

cia as visões que procuram justificar a xenofobia, o racismo, a marginalização e a exclusão social. Assim, os elementos fundantes de uma Ciranda Cartografia de Saberes estão inter-relacionados.

Em suma, imaginamos que esses passos na construção de um dispositivo metodológico pode favorecer o pesquisador a evidenciar memórias e conhecimentos de diferentes sujeitos, procurando, assim, entrelaçar novas possibilidades de conhecer e de socializar conhecimentos.

\section{Os entre-laços de saberes e conhecimentos em uma Ciranda Cartográ- fica de Saberes e Conhecimentos}

A Ciranda Cartográfica de Saberes e Conhecimentos, por nós proposta como um dispositivo de pesquisa, representa uma realidade e experiências que podem ser mapeadas/cartografadas para serem traduzidas e lidas como modo credível. Sob esse aspecto, Santos (2005, p. 201) nos lembra que os mapas distorcem uma realidade através de três mecanismos: a escala, a projeção e a simbolização.

Sobre isso, esclarecemos que, como mecanismo, a escala é, segundo Joly (1990, p. 20), a "[...] relação constante entre as distâncias lineares medidas sobre o mapa e as distâncias lineares correspondentes [...]", é o elemento que promove a representação/distorção da realidade. Quanto maior a escala maior será a possibilidade de elementos a serem desvendados.

A escala é um elemento de opacidade das múltiplas referências que estão presentes em uma realidade. Para Joly (1990, p. 8), ela determina um "[...] certo nível de análise em função do espaço a cobrir e dos detalhes a atingir [...] no estágio da redação, a escala é a condição da precisão, da legibilidade, da boa apresentação e da eficiência do mapa". Logo, a escala funciona como o elemento que desvela ou oculta situações. Contudo é preciso atentar que "um dado fenômeno só pode ser representado numa dada escala. Mudar de escala implica mudar o fenômeno" (Santos, 2005, p. 202).

$\mathrm{Na}$ Ciranda Cartografia de Saberes e Conhecimentos, a escala pode ser compreendida como a opção que fizemos em trazer à tona a fala de alguns sujeitos da pesquisa sem a preocupação de uma análise de discurso. Apenas as aproximamos a contextos e a situações diferentes.

A projeção é um elemento importante para a confecção de um mapa. Diferente de outras formas de retratar um espaço, a projeção, na cartografia, planifica dados. Para Santos (2005, p. 203), "cada tipo de projeção cria um campo de representação no qual as formas e os graus de distorção têm lugar segundo regras conhecidas e precisas". Em verdade, a projeção pode distorcer certa realidade tendo em vista a opção ideológica do cartógrafo e a finalidade/objetivo do mapa. Destacamos aqui que a projeção centraliza certo ponto e torna periféricos outros; essa atitude faz com que o conhecimento seja evidenciado de forma centralizadora. Sendo assim, a projeção na Ciranda 
Revista de la Escuela de Ciencias de la Educación, año 13, nRo. 12, vol. 1, enero a junio de 2017. Páginas 9-22. ISSN 1851-6297. ISSN 2362-3349 (EN LINEA). UMA PROPOSTA METODOLÓGICA: A CIRANDA CARTOGRÁFICA DE SABERES E CONHECImientos. Alcides Leão Santos Júnior

Cartográfica de Saberes e Conhecimentos refere-se à escolha em recortar falas e permitir que outras possam ser (re)lidas, mas nunca silenciadas.

Diante de uma complexidade de situações e da variedade de elementos presentes na realidade vivida pelos sujeitos, os símbolos gráficos sempre estiveram presentes. Nesse sentido, Joly (1990, p. 8) comenta que o "[...] número e o acúmulo dos símbolos empregados dependem, com efeito, do espaço disponível; quanto maior a redução da imagem terrestre (ou seja, quanto menor for à escala), mais severa é a seleção e mais abstrata a simbologia".

$\mathrm{Na}$ linguagem cartográfica, é fundamental uma convenção para que a leitura cartográfica seja mais rápida e eficaz. Todavia, esta não é uma regra geral, haja vista a utilização de legendas.

Santos (2005, p. 207) completa dizendo que a simbolização "[...] é a face visível da representação da realidade; é o procedimento técnico mais complexo, pois que a sua execução é condicionada tanto pelo tipo de escala, como pelo tipo de projeção adaptados".

Esses mecanismos (a escala, a projeção e a simbolização) são autônomos, "[...] envolvem procedimentos distintos e exigem decisões específicas" (Santos, 2005, p. 201). Assim, um mapa deve ser uma forma sintética/resumida de representação. Para tanto, precisa envolver o maior número de dados para uma leitura rápida e precisa.

Para a coleta dos dados, a utilização do questionário aberto, da entrevista semiestruturada e da análise documental podem favorecer a confecção de uma Ciranda Cartografia de Saberes e Conhecimentos. A utilização do questionário aberto se justifica pela possibilidade de uma maior aproximação com o pensamento dos sujeitos, propiciando-lhes a livre expressão, a análise e a crítica. Sugere-se elaborar questões indexalizadas ao contexto do estudo, apontando para as questões nucleares do problema de pesquisa; sugerindo aos respondentes que argumentem, justifiquem, contextualizem e explicitem as suas respostas. A entrevista semiestruturada possibilita o aprofundamento de questões emergentes durante a entrevista, oportunizando a construção de sentidos pelos entrevistados. Ela permite a compreensão de uma realidade que não se manifesta apenas a partir da linguagem oral porque, segundo Macedo (2000, p. 164), "[...] a linguagem aqui é um forte fator de mediação para a apreensão da realidade e não se restringe à noção de verbalização. Há toda uma gama de gestos e expressões densas de conteúdos indexais importantes para a compreensão das práticas cotidianas".

As entrevistas individuais e/ou coletivas quando aplicadas de modo aprofundado fomenta a minimização de dúvidas e esclarece ambiguidades, além de favorecer o entrelaçamento de experiências de vida. Por último, pode-se aplicar questionários abertos a fim de solucionar dificuldades decorrentes de participantes que se recusassem a conceder entrevista. Por tratar-se de uma pesquisa qualitativa após as entrevistas, que devem ser gravadas, procede- 
Revista de la Escuela de Ciencias de la Educación, año 13, nRo. 12, vol. 1, enero a Junio de 2017. PÁginas 9-22. ISSN 1851-6297. ISSN 2362-3349 (EN LíNEA). UMA PROPOSTA METODOLÓGICA: A CIRANDA CARTOGRÁFICA DE SABERES E CONHECImientos. Alcides Leão SANTOS JúNIOR

se com a transcrição das falas dos sujeitos. Visando tentar não promover um desperdício de experiências, ao realizar este procedimento, indica-se fazer uso da ecologia dos saberes e da tradução, pressupostos na Cartografia Simbólica (Santos, 2005, 2004, 2000), para criar a Ciranda Cartográfica de Saberes e Conhecimentos.

Cremos que este dispositivo de pesquisa tenta extrapolar os modos convencionais de confirmar hipóteses, pois se faz o uso da suspensão temporal e geográfica, da escala, da projeção e das distorções encontradas no processo da pesquisa e permite ao pesquisador entrelaçar memórias, saberes e conhecimentos de forma plástica. Neste sentido, postulamos que através de uma Ciranda Cartográfica de Saberes e Conhecimentos as memórias dos sujeitos estarão sendo valorizadas e através delas estamos produzindo um conhecimento por meio de saberes, de memórias e de experiências vividas.

Obviamente, estas são sugestões para a elaboração e delineamento de uma proposta. Outras formas de cartografar saberes e conhecimentos podem e devem surgir dependendo do objetivo e leitura de mundo do sujeito. Pois, como comenta Joly (1990, p. 17), os objetos cartografados são "[...] transcritos através de grafismos ou símbolos, que resultam de uma convenção proposta ao leitor pelo redator, e que é lembrada num quadro de sinais ou legenda do mapa".

Dentro de nossos limites, construímos a Ciranda Cartográfica de Saberes e Conhecimentos conforme a proposta de Santos (2002, p. 222) ressaltando que o sociólogo português sugere que vale "[...] a pena testar as virtualidades teóricas e analíticas da Cartografia Simbólica no estudo de outras representações sociais além do direito". $E$ foi isso que nos moveu à criação da Ciranda Cartográfica de Saberes e Conhecimentos, aqui apresentada, como modo singular de simbolização de entrelaçar vozes e experiências, de representação social de uma prática social e coletiva acreditando que a Cartografia viabiliza concretizar a realidade dos sujeitos que se utilizam dos mapas para dar sentido à construção de conhecimento, para concretizar e fazer sentido sua existência e práticas sociais e culturais, localizando-as no espaço e no tempo histórico.

Em suma, enfatizamos que para o entrelaçamento de saberes e conhecimentos pela via da Ciranda Cartográfica de Saberes e Conhecimentos é preciso ter claro que, sendo mapas, as experiências cartografadas são distorções reguladas de uma realidade, distorções organizadas de territórios que criam ilusões credíveis de correspondência, portanto o conhecimento produzido neste entrelaçamento é inacabado e está inserido na dinâmica da vida em sociedade que é mutável e permeável ao longo do tempo, mas que permite leituras no presente, do vivido no passado sempre capacitante. 
Revista de la Escuela de Ciencias de la Educación, año 13, nRo. 12, vol. 1, enero a junio de 2017. Páginas 9-22. ISSN 1851-6297. ISSN 2362-3349 (EN LINEA). UMA PROPOSTA METODOLÓGICA: A CIRANDA CARTOGRÁFICA DE SABERES E CONHECImientos. Alcides Leão Santos Júnior

\section{Considerações}

Tal como os mapas que direcionam caminhos ou até mostram o itinerário percorrido, a proposta de apresentar uma Ciranda Cartográfica de Saberes e Conhecimentos enquanto um dispositivo de pesquisa acadêmica traz as experiências e vivências dos sujeitos e nelas são evidenciadas lembranças do vivido.

Como as experiências vividas descritas em uma Ciranda Cartográfica de Saberes e Conhecimentos são memórias, lembramos que algumas distorções do vivido pelas brechas do tempo-histórico e social podem ser evidenciadas ou até mesmo não sendo apontadas pelo pesquisador. Mas, como um mapa que precisa de escalas e projeções, um olhar atento de outros sujeitos poderá a partir do que foi cartografada apontar novos caminhos. Com essa compreensão, podemos pensar que para operar esta metamorfose vale a pena frisar que se um mapa distorce uma realidade para instruir uma possível orientação às experiências e vivências, estas podem ter distorções do nosso ser/ estar em um tempo-espaço que nos concretiza como sujeitos.

Diante dessa perspectiva, distorções não caóticas, orientadas para um fim, o de fazer compreender que a experiência do outro não é sua, mas que contém saberes, práticas sociais e culturais que carecem ser visualizadas e respeitadas, precisamo-nos fazer ciência de procedimentos de pesquisas que procurem valorizar o "outro". Pois seus saberes podem ser necessários para nos situarmos em um tempo espaço-histórico e social que, embora não tenha sido experienciado por nós, poderá contribuir para que o mesmo se torne objeto cognoscente de nossas experiências de nossa construção de conhecimentos. Assim, tratamos a Ciranda Cartografia de Saberes e Conhecimentos como um dispositivo de pesquisa dialógico e político-social que, na sua dimensão emocional, pressupõe uma atitude inconformista em relação aos limites da produção de uma história única. Ela é uma postura de entrelaçamento de saberes e conhecimentos que permite chegar-se a um horizonte de entendimento em que as relações de poder cedem o lugar às relações de partilhas.

Por fim, para empreendermos uma investida em um trabalho desta natureza, é preciso salientar que a Ciranda Cartografia de Saberes e Conhecimentos surge como uma opção de trabalho que permite ao pesquisador uma maior aproximação com os sujeitos da sua pesquisa, bem como possibilita aos leitores novas possibilidades de leituras do que foi pesquisado, além de um rompimento com os pressupostos epistemológicos que direcionam, conduzem e norteiam a construção do conhecimento. É com essa percepção que os convido a cirandar com e entre os saberes e conhecimentos. 
Revista de la Escuela de Ciencias de la Educación, año 13, nRo. 12, vol. 1, enero a Junio de 2017. PÁginas 9-22. ISSN 1851-6297. ISSN 2362-3349 (EN LíNEA). UMA PROPOSTA METODOLÓGICA: A CIRANDA CARTOGRÁFICA DE SABERES E CONHECIMientos. Alcides Leão SANTOS JúNIOR

\section{Notas Bibliográficas}

(1) Utilizamos o termo dispositivo na acepção de Giorgio Agamben (2014, p.39) "chamarei literalmente de dispositivo qualquer coisa que tenha de algum modo à capacidade de capturar, orientar, determinar, interceptar, modelar, controlar e assegurar os gestos, as condutas, as opiniões e os discursos dos seres viventes". Ao longo de todo o texto, o termo dispositivo remete ao conjunto de artefatos utilizados para a produção do conhecimento no âmbito da extensão universitária.

\section{Referências Bibliográficas}

- Agamben, G. (2014). O amigo \& O que é um dispositivo? Chapecó/SC: Argos.

- Borba, S. (1998) Aspectos do conceito de multirreferencialidade nas ciências e nos espaços de formação. Em. J. Barbosa (Org.). Re exões em torno da abordagem multuirreferencial (pp. 11 - 19). São Carlos: Ed. UFSCar.

- Borba, S. (2012). Jacques Ardoino: espaços de formação, implicação e multirreferencia. In.

- Brito, F. J.; Hetkowski, T. M. (2009). Linguagem Cartográfica: discussão e contemporaneidade. Anais do IV Encontro Interdisciplinar de Cultura, Tecnologias e Educação - INTERCULTE. Disponível em: <www.unijorge.edu.br/pdfs/modelo artigo interculte.pdf> Acesso em Novembro de 2011.

- Cunha, T. (2006). Justiça Cognitiva, Identidades e Diásporas. O Cabo dos TrabaIhos. Revista Electrônica dos Programas de Mestrado e Doutoramento do CES/ FEUC/FLUC. N N 1. Coimbra. Disponível em <www.cabodostrabalhos.ces.uc.pt/ensaios.php> Acessado em maio de 2012.

- Duarte, P. A. (1991). Cartografia temática. Florianópolis: UFSC.

- Fleury, R. M. (2003). Intercultura e educação. Revista Brasileira de Educação. Maio/ Jun/Jul/Ago, 2 (23), 16-35.

- Joly, F. (1990). A cartografia. Trad. Tânia Pellegrini. 6 ed. São Paulo: Papirus.

- Macedo, R. S. (2000). A etnopesquisa crítica e multirreferencial nas Ciências - Humanas e na Educação. Salvador: EDUFBA.

- Macedo, R. S.; Barbosa, J. G.; Borba, S. (2012). (Org.). Jacques Ardoino e a Educação. Belo Horizonte: Editora Autêntica.

- Martins, J. B. (1998). Multirreferencialidade e educação. En. Barbosa, J. (Org.). Reflexões em torno da abordagem multuirreferencial. (pp. 21 - 34) São Carlos: EdUFSCar.

- Morin, E. (2007). Introdução ao pensamento complexo. Trad. Eliane Lisboa. 3 ed. Porto Alegre: Ed. Sulina.

- Nobre, I. (2003). A fotografia como narrativa visual. 2003. 146f. Tese de Doutorado (Doutorado em Ciências Sociais). Programa de Pós-Graduação em Ciências Sociais.Universidade Federal do Rio Grande do Norte. Natal/RN.

- Pimentel, A. G. (2012). Po(éticas) de formação nas traduções interculturais que vêm da periferia. En. Pimentel, A.G.; Galeffi, D.; Macedo, R. S. (2012) Po(Éticas) da formação: experimentações éticas e estéticas no acontecer formacional. (pp. 19 - 60) Salvador: EDUFBA. 
- Rodrigues, S. C.; Souza, L. H. (2008). Comunicação gráfica: bases conceituais para o entendimento da linguagem cartográfica. GEOUSP - Espaço e Tempo, São Paulo, 1 (23), 65-76.

- Santos, B. de S. (2005). Para um novo senso comum: a ciência, o direito e a política na transição paradigmática. 5 ed. São Paulo: Cortez. (v.1: A crítica da Razão indolente: contra o desperdício da experiência).

. (2000). A crítica da razão indolente: contra o desperdício da experiência. São Paulo: Cortez, 2000.

- _ (2004). O Fórum Social Mundial: manual de uso. Madison. Disponível em <www.ces.uc.pt/documentos/fsm.pdf>.

- ㄴ (2002). A Globalização e as Ciências Sociais. 2 ed. São Paulo: Cortez.

- ㄴ (2000). Pela mão de Alice: o social na pós-modernidade. 7. ed. São Paulo: Cortez.

- Santos, M. (2000). Por uma outra globalização: do pensamento único à consciência universal. São Paulo: Record.

- Santos Júnior, A. L. (2013) Extensão universitária e os entre-laços dos saberes. 247f. Tese de Doutorado (Programa de Pós Graduação em Educação). Universidade Federal da Bahia. Faculdade de Educação, Salvador/BA.

- Silva, L. L. S. (2006). Lembranças de alunos, imagens de professores: narrativase diálogos sobre formação médica. 186f. Dissertação (Mestrado em Ciências Sociais) Programa de Pós-Graduação em Ciências Sociais. Universidade Federal do Rio Grande doNorte. Natal/RN. 